\title{
Comparison of Fracture Resistance Between Two Monolithic and One Veneered Zirconia Materials on Molar Crowns After Thermomechanical Fatigue
}

\author{
Faisal Kayali $\mathbb{C}^{-}$, Erkut Kahramanoglu \\ Marmara University, Faculty of Dentistry, Department of Prosthodontics, Istanbul, Turkey. \\ Correspondence Author: Erkut Kahramanoglu \\ E-mail: erkut.kahramanoglu@marmara.edu.tr \\ Received: $21.08 .2020 \quad$ Accepted: 21.09 .2020
}

\begin{abstract}
Objective: The purpose of this in-vitro study is to evaluate fracture resistance of two monolithic and one veneered zirconia crowns on human molar teeth fabricated after thermomechanical fatigue.

Methods: Seventy-two human molar teeth were prepared to receive zirconia crowns. The specimens were divided into three experimental groups $(n=24)$ according to restoration design, monolithic or veneered. The crowns were fabricated from GC initial zirconia, Dentsply Sirona TZI and Dentsply Sirona ZI. The prepared teeth were scanned with Sirona inEos X5 and the restorations were milled using Cerec inLab MC X5. The crowns were cemented by resin cement. Twelve crowns of each experimental group underwent thermomechanical fatigue using chewing Simulator for 240000 chewing cycles with load of $(100 \mathrm{~N})$ and thermocycling $\left(5^{\circ} \mathrm{C} / 55^{\circ} \mathrm{C}\right)$, the remaining 12 crowns in each group did not undergo any thermomechanical fatigue and were considered as control group. All specimens were loaded until fracture using universal testing machine. Forces were applied to occlusal surface with $90^{\circ}$ angle. Loads of fracture were recorded. Collected data of fracture loads of all specimens were analyzed using SPSS 23.00 program.

Results: Although thermomechanical fatigue significantly decreased fracture loads of only monolithic groups, monolithic zirconia crowns had higher fracture loads than veneered one. Among all specimens, the highest fracture load was found in GC group (5001,81 N) and the lowest was found in Zl group ( $2117.37 \mathrm{~N}$ ). Two fracture patterns were observed among monolithic zirconia groups; total and crack, while three fracture patterns were observed in veneered group; porcelain fracture, porcelain and core, porcelain and core with tooth fracture.

Conclusion: Thermomechanical fatigue has significant influence on monolithic zirconia, however, it showed higher fracture loads and can be alternative to veneered design.

Keywords: Zirconia, monolithic, fracture, thermomechanical fatigue.
\end{abstract}

\section{INTRODUCTION}

Esthetics has become a crucial issue in modern communities. Until recently, functional demands were the main focus of restorative dentistry, however, the decrease of caries prevalence shifted the focus gradually from functional to esthetic dentistry which promoted the commercialization of newly introduced products. As a result, all-ceramic restorations are replacing metal-based restorations with wide range of ceramic systems being introduced in the market (1).

All-ceramic crowns showed similar survival rates with metal-ceramic crowns when they are indicated in the anterior dentition. Chipping and law fracture resistance associated with all-ceramic multilayered restorations are still popular cause of failure, strongly related to the location of the restoration. Molars has shown significantly higher fracture values than restorations in premolars and anterior teeth, $21 \%, 7 \%$, and $3 \%$, respectively. Traditional ceramics such as glass, glass-reinforced, and feldspathic ceramics and $\mathrm{AL}_{2} \mathrm{O}_{3}$-reinforced ceramics exhibited some complications, especially in the posterior dentition where occlusal forces are generally higher. Hence, great attempts have been expended in the growth of more efficient allceramic systems $(2,3)$.

Zirconia-based restorations emerged to be popular as they obtain high aesthetic potential, excellent biocompatibility with high mechanical and optical properties which let them to be used as a framework material. Studies on toothsupported zirconia-based restorations rarely reported complete fracture failures while no study reported complete fracture in implant-supported ones. ${ }^{2}$ On the other hand, most studies on bilayer restorations reported chip-off failure of the porcelain-veneer (3-6). These issues need to be taken 
in consideration although only few fractures caused the removal of restorations $(7,8)$.

New processing techniques were developed to encounter the chipping problem within ceramic veneering layers. Elimination the porosity produced within the veneering layer and injection of veneering porcelain over the zirconia framework. Further, techniques of CAD-on and rapid layering has become popular recently in prosthetic dentistry. Consequently, advances in CAD-CAM technology have expanded the range of restorations' material for both zirconia framework and veneer resulting almost flawless components as the ceramic blanks are fabricated industrially $(6,9,10)$.

As in other industries, production procedures are becoming automated more and more in dental technology. Many benefits are associated with CAD/CAM dental restorations such as: the accessibility to new, almost flawless, industrially produced and controlled materials; an enhancement in quality and reproducibility and data storage proportional with a standardized sequence of production; an advancement in precision and planning, as well as increased efficiency (11).

These improvements have resulted in a great change in the clinical workflow for dentists and dental technicians, as well as offering more treatment options to patients. Lithium silicate glass-ceramics reinforced with zirconia and composite constituted of a polymer-infiltrated ceramic are examples of these novel microstructures (12).

Many techniques have been carried out to improve the translucency and aesthetic properties of full-contour zirconia compared with conventional Y-TZP. These techniques included modifications on the fabrication processes, sintering temperature, addition of coloring liquids, increase in density and decrease in alumina content. A toughening mechanism of the transformation of tetragonal grains into the monoclinic phase leads to the high fracture toughness of zirconia, this transformation creates compressed stresses around defects, preventing their catastrophic diffusion. As a result, clinicians are now able to overcome one of the major problems associated to multilayered restorations as the issues regarding surface flaws and fracture of the lowstrength veneering layer can be avoided by using monolithic zirconia restorations $(12,13)$.

However, using monolithic zirconia restoration may arise other clinical complications which need to be taken in consideration, such as wear of the antagonist teeth and matching the aesthetic properties of the natural dentition. Although short-term data is available on high-strength zirconia materials, more research is still needed in cases of bruxism and periodontally compromised teeth $(12,14)$. The null hypothesis suggests that thermomechanical fatigue would have significant influence on fracture resistance of all materials, however, monolithic zirconia groups would exhibit similar fracture loads but higher than veneered zirconia after thermomechanical fatigue.
The purpose of this in-vitro study is to evaluate fracture resistance of two monolithic and one veneered zirconia crowns on human molar teeth fabricated after thermomechanical fatigue.

\section{METHODS}

This study was approved by the ethic committee of Marmara University, Faculty of Dentistry in Istanbul, Turkey (Protocol number 260/2018).

A total of 72 extracted human molars, free of carries and restorations were selected for the study. Dental plaque, calculus and external debris were removed with an ultrasonic scaler and immersed in a germfree $0.1 \%$ thymol solution at room temperature for 1 day then all teeth were mounted individually in acrylic resin. The specimens were randomly divided into three experimental groups $(n=24)$ according to restoration design.

All teeth were prepared according to a standardized protocol as follows: $1.2 \mathrm{~mm}$ chamfer finish line positioned $1 \mathrm{~mm}$ occlusal to the CEJ and $6^{\circ}$ convergent axial walls. All sharp or internal line angles were rounded, and undercuts were avoided. Occlusal reduction of $1.5 \mathrm{~mm}$ was determined to all specimens (Fig. 1). All teeth were prepared by a single dentist, and standardized crown preparation was accomplished by fixing the dental handpiece in a parallelometer. A single-stage impression technique using putty and light-bodied vinyl polysiloxane (Zhermack Elite $\mathrm{HD}+$, Badia Polesine, Italy) material was made then were poured with dental stone type IV (Fujirock EP, GC Europe, Leuven, Belgium).
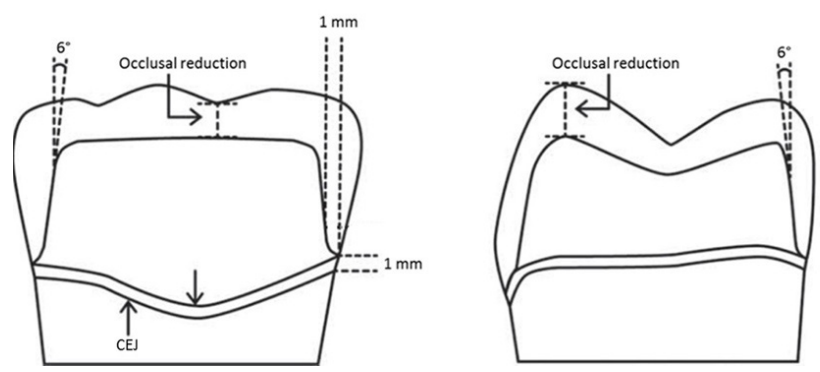

Figure 1. Illustration of the abutment tooth of monolithic crowns showing width of chamfer finish line, convergent of axial walls and occlusal reduction.

72 restorations were made using Cerec inLab CAD/CAM (Dentsply Sirona, Germany, Bensheim) system from three different materials; GC Initial (GC Europe, Leuven, Belgium), Dentsply Sirona TZI and Dentsply Sirona ZI (Dentsply Sirona, Germany, Bensheim).

A digital impression was taken for all dies using inEos $X 5$. Then, the restorations design was made by single experienced dental technician. Monolithic restorations were designed with full anatomy and veneered restorations with anatomical design. A standard of 1.5 
$\mathrm{mm}$ occlusal thickness was determined for all groups. For ZI group, a thickness of $0.8 \mathrm{~mm}$ was determined for the zirconia core and $0.7 \mathrm{~mm}$ for hand-layered veneering porcelain (IPS e.max Ceram A2, Ivoclar Vivadent, Schaan, Liechtenstein) to result in total occlusal thickness of 1.5 $\mathrm{mm}$ in a commercial dental laboratory (Optimal Dental Laboratory, Istanbul, Turkey). Thickness standardization was carried out by measuring and adjusting the thickness at 10 different points on the occlusal surface using the CAD software to insure the standardized occlusal thicknesses of $1.5 \mathrm{~mm}$ (Fig. 2).

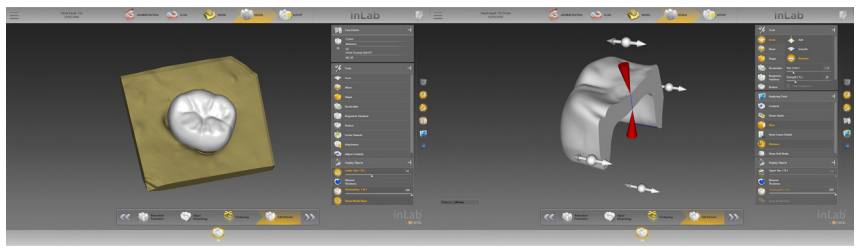

Figure 2. Restoration design and adjustment of occlusal thickness using inLab CAD software.

After design, restorations were sent to a milling unit inLab MC X5 (Dentsply Sirona, Germany, Bensheim) and new set of CAD/CAM milling burs was used for each group. Then sintering was carried out for all groups with classic program using inFire HTC speed (Dentsply Sirona, Bensheim, Germany) according to the manufacturer instructions then all specimens were glazed.

Fit of crowns was evaluated by the same dental technician to ensure complete adaptation. All specimens were dried with oil free compressed air and cemented with dual-cure selfadhesive resin cement (G-Cem LinkAce, GC, Tokyo, Japan). Cementation was carried out individually to all crowns according to the manufacturer instructions as following: each restoration was coated with sufficient amount of cement then immediately seated on the prepared tooth and firm finger pressure was applied in the direction of insertion. Excess cement was removed using a surgical blade (AESCULAP no. 12, Aesculap AG \& Co, Tuttlingen, Germany) after tack curing 1-2 seconds, then each surface was light cured using curing unit for 20 seconds and left for self-cure for four minutes.

Twelve crowns of each experimental group were subjected to thermomechanical fatigue (TMF) using chewing simulator (Willytec SD Mechatronic GmbH CS-4.4 Professional Line, Feldkirchen-Westerham, Germany) and the other 12 crowns were considered as control specimens without any fatigue. To simulate 1 year of clinical service, a total of 240000 loading cycles was performed. The load was vertically applied to the central occlusal fossa of the crowns with a steel antagonist ball of $6 \mathrm{~mm}$ in diameter and at $1.7 \mathrm{~Hz}$ frequency. In addition, the simulator includes a thermocycling system, using magnetic valves in conjunction with a heating and cooling system controlled by PLCs. The test chambers were flooded using deionized water with a temperature of $5^{\circ} \mathrm{C}$ for $30 \mathrm{sec}$ and -after evacuation- with a temperature of $55^{\circ} \mathrm{C}$ for $30 \mathrm{sec}$ to result a total of 3000 thermal cycle (Fig. 3).

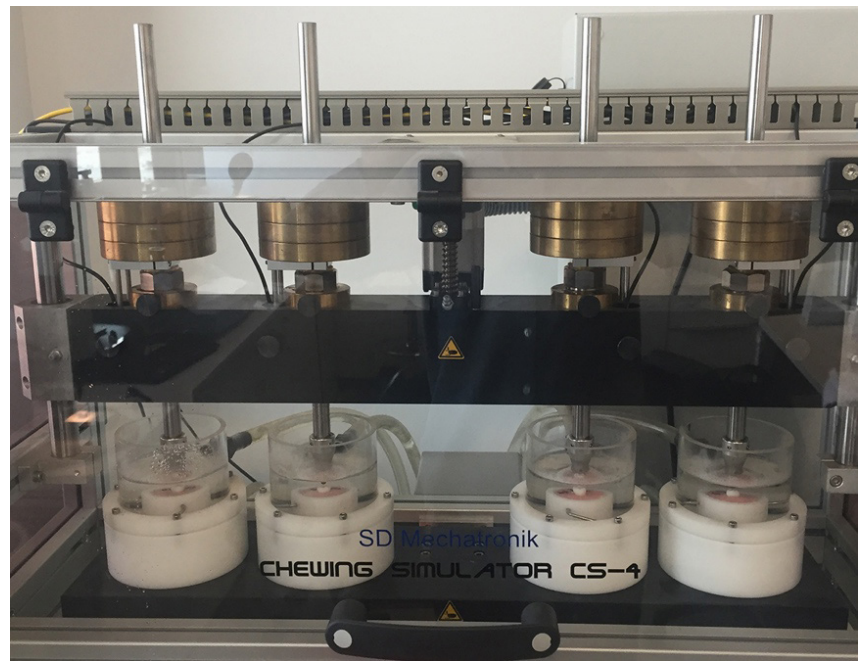

Figure 3.Specimen fixed inside thermomechanical fatigue station.

The fracture resistance test was performed with a universal testing machine (Shimadzu, model no:133.064.800195, Kyoto, Japan). A steel ball of $6 \mathrm{~mm}$ diameter at a crosshead speed of $1 \mathrm{~mm} / \mathrm{min}$ was used for loading. All samples were loaded until fracture and the maximum breaking loads were recorded in Newtons (N).

The recorded data of fracture loads were statistically analyzed with a dedicated software (SPSS 23,00, SPSS Inc., Chicago, IL, USA). Loads at fracture were analyzed with the one-way ANOVA with descriptive and Post Hoc multiple comparisons according to Tukey. For all the statistical tests, the level of significance was set at $\mathrm{P}=0,05$.

\section{RESULTS}

All specimens of TMF subgroups withstood thermomechanical fatigue in chewing simulator. Analysis of the results showed a statistically significant influence of thermomechanical fatigue on fracture resistance in both monolithic zirconia groups $(P<0.05)$ while it didn't have statistically significant influence on veneered zirconia ( $P>0.05)$. Among all specimens, the highest fracture load was found in GC group (5001,81 N) and the lowest was found in $\mathrm{Zl}$ group (2117.37 N). Among only control groups, GC showed the highest mean fracture resistance value $(4626,65 \mathrm{~N})$ while TZI material showed the highest mean fracture resistance value $(3459,27 \mathrm{~N})$ among TMF groups (Table 1). 
Table 1. Fracture loads of each group (Mean, SD, Minimum, Maximum).

\begin{tabular}{|c|c|c|c|c|c|}
\hline \multicolumn{2}{|c|}{ Group } & $\begin{array}{c}\text { Mean } \\
(\mathrm{N})\end{array}$ & $\begin{array}{l}\text { SD } \\
(N)\end{array}$ & $\begin{array}{l}\text { Minimum } \\
\text { (N) }\end{array}$ & $\begin{array}{c}\text { Maximum } \\
\text { (N) }\end{array}$ \\
\hline \multirow[b]{2}{*}{$\begin{array}{l}\text { GC } \\
(n: 24)\end{array}$} & $\begin{array}{l}\text { C } \\
(n: 12)\end{array}$ & 4626,65 & 267,93 & 4218,04 & 5001,81 \\
\hline & $\begin{array}{l}\text { TMF } \\
(\mathrm{n}: 12)\end{array}$ & 3297,67 & 330,69 & 2864,77 & 3870,49 \\
\hline \multirow[b]{2}{*}{$\begin{array}{l}\text { TZI } \\
(n: 24)\end{array}$} & $\begin{array}{l}\text { C } \\
(n: 12)\end{array}$ & 4602,55 & 449,81 & 3549,84 & 5001,59 \\
\hline & $\begin{array}{l}\text { TMF } \\
(n: 12)\end{array}$ & 3459,27 & 522,23 & 2858,71 & 4141,09 \\
\hline \multirow[b]{2}{*}{$\begin{array}{l}\mathrm{Zl} \\
(\mathrm{n}: 24)\end{array}$} & $\begin{array}{l}\text { C } \\
(n: 12)\end{array}$ & 2958,43 & 460,53 & 2397,82 & 3552,77 \\
\hline & $\begin{array}{l}\text { TMF } \\
(n: 12)\end{array}$ & 2868,58 & 408,84 & 2117,37 & 3489,03 \\
\hline
\end{tabular}

The results of ANOVA showed statistically significant difference between experimental groups (Table 2). Tukey results showed that both monolithic zirconia materials exhibited statistically similar fracture loads in control $(p=1,000)$ and TMF groups $(p=0,931)$ but higher than veneered zirconia in both groups. Although, after TMF only TZI specimens showed statistically significant difference $(p=0,048)$ from veneered zirconia control group (Table 3 )

Table 2. One-way ANOVA test.

\begin{tabular}{|l|c|c|c|c|c|}
\hline $\begin{array}{l}\text { Between all } \\
\text { subgroups }\end{array}$ & 18824129,599 & 2 & 9412064,799 & 21,736 &, 000 \\
\hline $\begin{array}{l}\text { Within } \\
\text { subgroups }\end{array}$ & 29878212,783 & 69 & 433017,577 & & \\
\hline Total & 48702342,381 & 71 & & & \\
\hline
\end{tabular}

Table 3. Post Hoc Tukey tests.

\begin{tabular}{|c|c|c|c|c|}
\hline \multirow{2}{*}{\multicolumn{2}{|c|}{ Group }} & \multirow{2}{*}{ Sig. } & \multicolumn{2}{|c|}{ 95\% Confidence Interval } \\
\hline & & & Lower Bound & Upper Bound \\
\hline \multirow{5}{*}{$\mathrm{GC}(\mathrm{C})$} & GC (TMF) & ,000 & 831,2010 & 1826,7624 \\
\hline & TZI (C) & 1,000 & $-473,6815$ & 521,8799 \\
\hline & TZI (TMF) &, 000 & 669,5985 & 1665,1599 \\
\hline & $\mathrm{ZI}(\mathrm{C})$ &, 000 & 1170,4443 & 2166,0057 \\
\hline & Zl (TMF) &, 000 & 1260,2926 & 2255,8540 \\
\hline \multirow{5}{*}{ GC (TMF) } & $\mathrm{GC}(\mathrm{C})$ &, 000 & $-1826,7624$ & $-831,2010$ \\
\hline & TZI (C) & ,000 & $-1802,6632$ & $-807,1018$ \\
\hline & TZI (TMF) & ,931 & $-659,3832$ & 336,1782 \\
\hline & ZI (C) & ,353 & $-158,5374$ & 837,0240 \\
\hline & ZI (TMF) & ,023 & $-68,6890$ & 926,8724 \\
\hline \multirow{5}{*}{ TZI (C) } & $\mathrm{GC}(\mathrm{C})$ & 1,000 & $-521,8799$ & 473,6815 \\
\hline & GC (TMF) &, 000 & 807,1018 & 1802,6632 \\
\hline & TZI (TMF) & ,000 & 645,4993 & 1641,0607 \\
\hline & $\mathrm{ZI}(\mathrm{C})$ &, 000 & 1146,3451 & 2141,9065 \\
\hline & ZI (TMF) & ,000 & 1236,1935 & 2231,7549 \\
\hline \multirow{5}{*}{ TZI (TMF) } & $\mathrm{GC}(\mathrm{C})$ &, 000 & $-1665,1599$ & $-669,5985$ \\
\hline & GC (TMF) & 931 & $-336,1782$ & 659,3832 \\
\hline & TZI (C) &, 000 & $-1641,0607$ & $-645,4993$ \\
\hline & $\mathrm{ZI}(\mathrm{C})$ & ,048 & 3,0651 & 998,6265 \\
\hline & ZI (TMF) & ,011 & 92,9135 & 1088,4749 \\
\hline \multirow{5}{*}{$\mathrm{ZI}(\mathrm{C})$} & $\mathrm{GC}(\mathrm{C})$ & ,000 & $-2166,0057$ & $-1170,4443$ \\
\hline & GC (TMF) &, 353 & $-837,0240$ & 158,5374 \\
\hline & TZI (C) & ,000 & $-2141,9065$ & $-1146,3451$ \\
\hline & TZI (TMF) & ,048 & $-998,6265$ & $-3,0651$ \\
\hline & ZI (TMF) & ,995 & $-407,9324$ & 587,6290 \\
\hline \multirow{5}{*}{ ZI (TMF) } & $\mathrm{GC}(\mathrm{C})$ &, 000 & $-2255,8540$ & $-1260,2926$ \\
\hline & GC (TMF) & ,023 & $-926,8724$ & 68,6890 \\
\hline & TZI (C) &, 000 & $-2231,7549$ & $-1236,1935$ \\
\hline & TZI (TMF) & ,011 & $-1088,4749$ & $-92,9135$ \\
\hline & ZI (C) & ,995 & $-587,6290$ & 407,9324 \\
\hline
\end{tabular}

In the present study, two fracture patterns were observed among monolithic zirconia groups; total and crack (Fig 4). While all TZI specimens' pattern was only total fracture, GC group specimens showed two patterns; 7 total fracture and 5 crack for both control and TMF groups (Table 4).

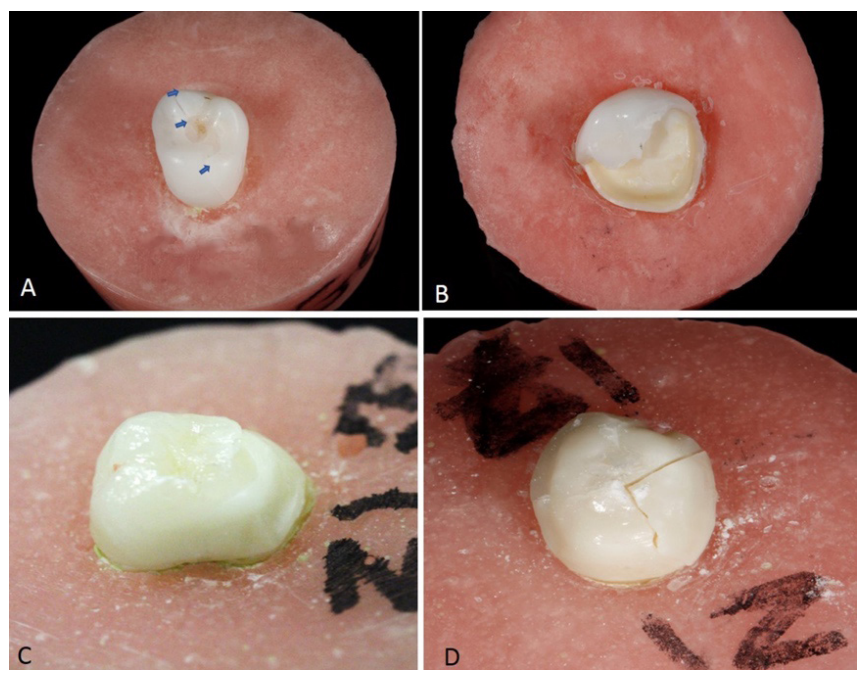

Figure 4. Failure patterns of monolithic crowns (A: crack, B: total fracture) and veneered crowns

(C: fracture of lingual cusp porcelain D: fracture of porcelain and core)

Table 4. Failure patterns of experimental groups.

\begin{tabular}{|c|c|c|c|c|c|c|}
\hline \multirow{2}{*}{\multicolumn{2}{|c|}{ Material }} & \multicolumn{5}{|c|}{$\begin{array}{l}\text { Failure patterns } \\
\text { during fracture test }\end{array}$} \\
\hline & & P & $P+C$ & $\mathrm{P}+\mathrm{C}+\mathrm{T}$ & Crack & Total \\
\hline \multirow{2}{*}{ GC } & C & - & - & - & 5 & 7 \\
\hline & TMF & - & - & - & 5 & 7 \\
\hline \multirow{2}{*}{ TZI } & C & - & - & - & 0 & 12 \\
\hline & TMF & - & - & - & 0 & 12 \\
\hline \multirow{2}{*}{ Zl } & $C$ & 7 & 3 & 2 & - & - \\
\hline & TMF & 9 & 2 & 1 & - & - \\
\hline
\end{tabular}

*P: porcelain fracture, C: core fracture, $\mathrm{T}$ : tooth fracture

Three fracture patterns were observed in veneered group; porcelain fracture $(P)$, porcelain and core $(P+C)$, porcelain and core with tooth fracture (P+C+T) (Fig. 4). In Zl control group 7 $P, 3 P+C$ and $2 P+C+T$ were observed, on the other hand $9 P$, $2 \mathrm{P}+\mathrm{C}$ and $1 \mathrm{P}+\mathrm{C}+\mathrm{T}$ were observed in $\mathrm{ZI}$ TMF group. No failure was observed during TMF test in the chewing simulator, but wear occurred at contact points of some specimens (Table 4).

\section{DISCUSSION}

The results of the present study led to partially reject the first hypothesis, as thermomechanical fatigue significantly decreased fracture resistance of only monolithic zirconia 
while it didn't have significant effect on veneered zirconia. On the other hand, the second hypothesis was accepted as monolithic zirconia groups exhibited similar fracture loads but higher than veneered zirconia.

The increase of esthetics' interest has led to the production of metal-free restorations. Dental ceramics exhibits several adequate features like biocompatibility which makes them excellent choice to simulate the features of natural teeth. Bilayer systems demonstrated several drawbacks including the low strength of the veneering material, multistep manufacturing process, and the weak bond between coping and veneer layer as the most common reported complication is chipping or cracking of the porcelain veneer. Therefore, efforts to overcome this complication have included improving the veneering ceramic firing protocol, modifying the core design, using the over-pressing technique, and using CAD-CAM veneering (CAD-on) and monolithic restorations. Thus, it seemed appropriate to provide actual evidence on fracture rates of all-ceramic zirconia crowns comparing monolithic and veneered zirconia restorations.

The abutment material plays a crucial role in evaluating the strength of dental restorative materials as it affects the mechanical properties and fracture resistance. Heintze et al.(15), and Preis et al.(6), used PMMA (Poly methyl methacrylate) abutments to test the fracture probability of all-ceramic crowns with a chewing simulator. These abutments can be a dependable artificial alternative that helps for a better standardization in fabricating identical restorations for more reliable comparison as mentioned by Dinesh et al.(16) study in 2015. On the other hand, Nakamura et al. (17) and Güngör et al. (5) used plastic Frasaco tooth as abutments. Lopez-Suarez et al.(18) used metal abutments in their study on metal ceramic, monolithic and veneered zirconia restorations. In the present study, natural teeth were used as abutments to ensure relevant strength data comparable with the clinical conditions.

Nakamura et al.(17) studied the effect of different cements on fracture resistance of monolithic zirconia crowns, they used zinc phosphate cement, glass ionomer cement, selfadhesive resin-based cement and resin-based cement. Their results didn't show influence of cement type on fracture strength. Preis et al.(6), used dual-curing resin (Variolink) to cement monolithic and veneered zirconia, while Sorrentino et al., 2016 used dual-cure self-adhesive universal resin cement (G-Cem LinkAce) to cement monolithic zirconia. This resin cement contains unique phosphate monomers that chemically bond to zirconia, for a strong and stable bond. The literature data emphasize the clear advantageous effect of phosphate monomers on bond strength zirconia/luting cements associated with mechanical pretreatments (airborne particle) in order to achieve enduring bond values $(18,19)$. In the present study, dual-cure self-adhesive resin (G-Cem LinkAce, GC, Tokyo, Japan) was chosen and cementation was carried out according to manufacturer instructions.

The application of artificial aging has been an essential aspect in any in-vitro study regarding fracture strength to gain realistic results of fracture loads. Rosentritt et al. (20) reported that artificial aging should be performed combining thermal cycling with mechanical loading to simulate the oral environment. However, huge range of cycles' number and vertical loading values were performed in artificial aging data in the literature, with in-vitro studies performing 5000 to 400000 cycles $(20-22,24)$. Certainly, many studies applied 1 200000 cycles with $50 \mathrm{~N}$ of vertical load for 5 years of service $(6,21)$. For the present study, 240000 cycles were selected to simulate 1 year of clinical service. The parameters of thermomechanical fatigue have been chosen in accordance to numerous other in vitro studies (26-28).

The results of the present study indicate a stable performance of zirconia-based crowns after 1 year of clinical service. The absence of failures during TMF as well as the high fracture loads of all groups evaluated in this study may be explained by the high mechanical properties of zirconia, especially high strength, hardness and resistance to crack propagation compared to porcelain. The toughness of zirconia has been addressed in the literature intensively, and it is attributed to a local "toughing transformation" from tetragonal to monoclinic phase upon external application of stress (6). Fracture loads of monolithic zirconia has been significantly decreased by thermomechanical fatigue compared to control groups, this result is consistent with similar studies in which they found that monolithic zirconia is clearly affected by thermomechanical fatigue $(4,29)$. This can be explained by the tendency of zirconia to low temperature degradation (LTD) which is mainly initiated in moist environment $(4,30)$. On the other hand, although fracture loads of veneered zirconia slightly decreased after TMF, no statistical difference was observed in the present study when compared to control group. The result of this study differs from studies showing that thermomechanical fatigue reduces the fracture resistance in veneered zirconia (20-31). This difference could be due to the different methodologies employed, that include the type of the restoration analyzed (crown or FPD), the type of die employed, or the number of cycles and the force applied during the thermomechanical loading.

Accordingly, previous studies evaluating the fracture strength of all-ceramic monolithic crowns demonstrated excellent performance of the monolithic design over the veneered one $(11,12,38)$. The enhanced performance of monolithic crowns may be caused by the elimination of the interface between core and veneer, which is believed to be the fragile link in bilayer systems (3). Furthermore, fabricating CAD/CAM restorations involves high quality material with a minimum flaw compared to the manual veneering process. The results of the present study showed that both monolithic zirconia materials exhibited statistically similar fracture loads but higher than veneered zirconia in both control and TMF groups.

In the present study, the predominant fracture pattern of monolithic crowns was total fracture while only $20 \%$ had crack. This result was expected, since these crowns have only one material layer which leads to a bulk structural fracture. 
These patterns are in accordance to the studies by Sun et al.(36) and Nordahl et al.(37). On the other hand, veneering layer fracture was the predominant fracture pattern in veneered zirconia group similarly to other studies $(5,36,38)$. The procedures of conventional layering technique and the low mechanical features of the veneering material may be the reason for chipping failure pattern.

All evaluated materials in the present study showed values that surpasses the predictable average maximum loads with safe margin, demonstrating adequate fracture resistance, as the lowest mean value $(2868,58 \mathrm{~N})$. Nevertheless, fractures in veneering layer, which is a popular complication in the clinical practice, have been reported by several clinical studies rather than complete fractures. In summary, monolithic zirconia crowns arise to be a considerable alternative, especially in cases with previous fractured restorations. More clinical evaluation is needed, to assert the outcome of this in-vitro study.

\section{Limitations of the study}

In the present in vitro study, standardized conditions were provided for every experimental procedure, however, limitations of this study may include: the use of natural teeth helped to simulate clinical conditions, that did not ensure optimal standardization of the abutments. A further limiting factor may be the use of steel antagonist ball instead of human tooth as antagonists in chewing simulator. Although the steel ball sphere assured a standardized antagonistic condition (6). Analyzing with prolonged TMF simulation duration might be necessary to obtain better evaluation of the in-vitro performance of the different groups of zirconiabased materials.

\section{CONCLUSION}

Within the limitation of the present study, the following can be concluded: monolithic zirconia exhibits higher fracture resistance than veneered zirconia. However, thermomechanical fatigue has shown more significant influence on fracture resistance of monolithic zirconia than veneered. Therefore, they could be used in load-bearing areas without the chipping problem as frequently observed in their veneered counterpart.

\section{REFERENCES}

[1] Samorodnitzky-Naveh GR, Geiger SB, Levin L. Patients' satisfaction with dental esthetics. Journal of the American Dental Association 2007;138:805-808.

[2] Pozzi A, Tallarico M, Barlattani A. Monolithic lithium disilicate full-contour crowns bonded on CAD/CAM zirconia completearch implant bridges with 3 to 5 years of follow-up. Journal of Oral Implantology 2015;41:450-458.

[3] Lameira DP, Buarque e Silva WA, Andrade e Silva F, De Souza GM. Fracture strength of aged monolithic and bilayer zirconiabased crowns. Biomed Research International 2015;418641.
[4] López-Suáreza C, Castillo-Oyagüea R, Rodríguez-Alonsoa V, D. Lynchb C, Suárez-García M. Fracture load of metal-ceramic, monolithic, and bi-layered zirconia-based posterior fixed dental prostheses after thermo-mechanical cycling. Journal of Dentistry 2018;73:97-104.

[5] Güngör MB, Nemli SK. Fracture resistance of CAD-CAM monolithic ceramic and veneered zirconia molar crowns after aging in a mastication simulator. Journal of Prosthetic Dentistry 2018;119(3):473-480.

[6] Preis V, Behr M, Hahnel S, Handel G, Rosentritt M. In vitro failure and fracture resistance of veneered and full-contour zirconia restorations. Journal of Dentistry 2012;11:921-928.

[7] Daou E. The zirconia restoration properties: a versatile restorative material. Open Dentistry Journal 2014;8:33-42.

[8] Guess PC, Zavanelli RA, Silva NR, Bonfante EA, Coelho PG, Thompson VP. Monolithic CAD/CAM lithium disilicate versus veneered Y-TZP crowns: comparison of failure modes and reliability after fatigue. International Journal of Prosthodontics 2010; 25:434-442.

[9] Sarıkaya I, Hayran Y. Effects of dynamic aging on the wear and fracture strength of monolithic zirconia restorations. BMC Oral Health 2018; 1:146.

[10] Schmitter M, Mueller D, Rues S. In vitro chipping behavior of all-ceramic crowns with a zirconia framework and feldspathic veneering: comparison of CAD/CAM-produced veneer with manually layered veneer. Journal of Oral Rehabilitation 2013; 40:519-525.

[11] Beuer F, Schweiger J, Edelhoff D. Digital dentistry: an overview of recent developments for CAD/CAM generated restorations. British Dental Journal 2008; 204:505-511.

[12] Silva LHD, Lima E, Miranda RBP, Favero SS, Lohbauer U, Cesar PF. Dental ceramics: a review of new materials and processing methods. Brazilian Oral Research 2017; 31:e58.

[13] Zhang Y, Lee JJ, Srikanth R, Lawn BR, Edge chipping and flexural resistance of monolithic ceramics. Dental Materials 2013; 29(12):1201-1208.

[14] Raut A, Rao PL, Ravindranath T. Zirconium for esthetic rehabilitation: an overview. Indian Journal of Dental Research 2011; 22:140-143.

[15] Heintze SD, Faouzi M, Rousson V, Ozcan M. Correlation of wear invivo and six laboratory wear methods. Dental Materials 2012; 28:961-973.

[16] Dinesh KS, Anandan R, Ekanthamoorthy J. Advances in DentalPMMA based artificial teeth through Rapid Prototyping technology. Biomedical Research 2015; 26(4):6-8.

[17] Nakamura K, Harada A, Inagaki R, Kanno T, Niwano Y, Milleding $P$, Ortengren $U$. Fracture resistance of monolithic zirconia molar crowns with reduced thickness. Acta Odontologica Scandinavica 2015; 73(8):602-628.

[18] Lopez-Suarez C, Tobar C, Sola-Ruiz MF, Pelaez J, Suarez MJ. Effect of thermomechanical and static loading on the load to fracture of metal-ceramic, monolithic, and veneered zirconia posterior fixed partial dentures. Journal of Prosthodontics 2019; 28(2):171-178.

[19] Mirmohammadi H. Aboushelib M, Salameh Z, Kleverlaan CJ. Influence of enzymatic and chemical degradation on zirconia resin bond strength after different surface treatments. American Journal of Dentistry 2010; 23(6):327-330.

[20] Rosentritt M, Behr M, Gebhard R, Handel G. Influence of stress simulation parameters on the fracture strength of all-ceramic 
fixed-partial dentures. Dental Materials Journal. 2006; 22(2):176-182.

[21] Dbradović-Djuricić K1, Medić V, Dodić S, Gavrilov D, Antonijević D, Zrilić M. Dilemmas in zirconia bonding: a review. Serbian Archives of Medicine 2013; 141(5-6):395-401.

[22] Burgess JO, Janyavula S, Lawson NC, Lucas TJ, Cakir D. Enamel wear opposing polished and aged zirconia. Operative Dentistry 2014; 39(2):189-192.

[23] Kontos L1, Schille C, Schweizer E, Geis-Gerstorfer J. Influence of surface treatment on the wear of solid zirconia. Acta Odontologica Scandinavica 2013; 71(3-4):482-487.

[24] Luangruangrong P, Cook NB, Sabrah AH, Hara AT, Bottino MC. Influence of full-contour zirconia surface roughness on wear of glass-ceramics. Journal of Prosthodontics 2014; 23(3):198205.

[25] Kim MJ, Oh SH, Kim JH, Ju SW. Wear evaluation of the human enamel opposing different Y-TZP dental ceramics and other porcelains. Journal of Dentistry 2012; 40(11):979-988.

[26] Stawarczyk B, Ozcan M, Schmutz F, Trottmann A, Roos M, Hammerle $\mathrm{CH}$. Two-body wear of monolithic, veneered and glazed zirconia and their corresponding enamel antagonists. Acta Odontologica Scandinavica 2013; 71:102-112.

[27] Habip SR, Alotaibi A, Hazza NA, Allam Y, AlGhazi M. Two-body wear behavior of human enamel versus monolithic zirconia, lithium disilicate, ceramometal and composite resin. Journal of Advanced Prosthodontics 2019; 11(1):23-31.

[28] Ruben JL, Roeters JM, Montagner AF, Huysmans MCDNJM. A multifunctional device to simulate oral ageing: the "Rub\&Roll". Journal of Mechanical Behaviour of Biomedical Materials 2014; 30:75-82.

[29] Mitov G, Anastassova-Yoshida Y, Nothdurft FP, von See C, Pospiech P. Influence of the preparation design and artificial aging on the fracture resistance of monolithic zirconia crowns. Journal of Advanced Prosthodontics 2016; 8(1):30-36.
[30] Kern F, Lindner V, Gadow R. Low-temperature degradation behaviour and mechanical properties of a 3Y-TZP manufactured from detonation-synthesized powder. Journal of Ceramic Science and Technology 2016; 7(04):313-322.

[31] Vidotti HA, Pereira JR, Insaurralde E, et al: Thermo and mechanical cycling and veneering method do not influence. Y-TZP core/veneer interface bond strength. Journal of Dentistry 2013;41:307-312.

[32] Borchers L, Stiesch M, Bach FW, Buhl JC, Hübsch C, Kellner $\mathrm{T}$, Kohorst $\mathrm{P}$, Jendras $\mathrm{M}$. Influence of hydrothermal and mechanical conditions on the strength of zirconia. Journal of Advanced Prosthodontics 2014;6(6):462-467.

[33] Borba M, De Araújo MD, Fukushima KA, Yoshimura HN, Griggs J, Della Bona A, Cesar PF. Effect of different aging methods on the mechanical behavior of multi-layered ceramic structures Dental Materials. 2016;32(12):1536-1542.

[34] Yang R, Arola D, Han Z, Zhang X. A comparison of the fracture resistance of three machinable ceramics after thermal and mechanical fatigue. Journal of Prosthetic Dentistry. 2014;112(4):878-885.

[35] Kohorst P, Dittmer MP, Borchers L, Stiesch-Scholz M. Influence of cyclic fatigue in water on the load-bearing capacity of dental bridges made of zirconia. Acta Biomaterialia 2008;4(5):14401447.

[36] Sun T, Zhou S, Lai R, Liu R, Ma S, Zhou Z, Longquan S. Loadbearing capacity and the recommended thickness of dental monolithic zirconia single crowns. Journal of the Mechanical Behavior of Biomedical Materials 2014;35:93-101.

[37] Nordahl N, Vult von Steyern P, Larsson C. Fracture strength of ceramic monolithic crown systems of different thickness. Journal of Oral Science 2015;57(3):255-261.

[38] Beuer F, Stimmelmayr M, Gueth JF, Edelhoff D, Naumann M. In vitro performance of full-contour zirconia single crowns. Dental Materials Journal 2012;28:449-456.

How to cite this article: Kayali F, Kahramanoglu E. Comparison of Fracture Resistance Between Two Monolithic and One Veneered Zirconia Materials on Molar Crowns After Thermomechanical Fatigue. Clin Exp Health Sci 2020; 10: 320-326. DOI: 10.33808/ clinexphealthsci.783438 